\title{
Evaluation of Ear, Nose and Throat Foreign Bodies in the Department of ENT-Head and Neck Surgery in a Teaching Hospital
}

\author{
Bishow Tulachan*, Abishesh Shakya, Paras Poudel and BN Borgohain \\ Department of ENT-Head and Neck Studies, Universal College of Medical Sciences, Nepal
}

*Corresponding author: Bishow Tulachan, Department of ENT-Head and Neck Studies, Universal College of Medical Sciences, Nepal

\begin{abstract}
Objective: FB (foreign bodies) in ear, nose and throat are often encountered by otolaryngologists in their daily practice and is commonly seen in both children and adults. Depending upon the type and location of FB, it may have serious impact on individual's health if instant appropriate action is not taken. That's why, there's frequent visits to ED (emergency department) on having FB in ear and aerodigestive tracts. The objective of this study was to evaluate the nature, common sites, modes of presentation, modes of management of FB, age and gender distribution.

Materials and Methods: A retrospective hospital-based study was done in Universal College of Medical Sciences, Bhairahawa, Rupandehi, Nepal from March 2014 to September 2017. The information was obtained from hospital record books.

Results: Out of 483 total patients, 287 (59.42\%) were male and 196 (40.57\%) were female. Most of them were less than 10 years old. Of the 483 patients, $202(41.82 \%)$ had FB in the ear, $132(27.32 \%)$ in the nose and $149(30.84 \%)$ in the throat. Living FB were found in $54(26.73 \%)$ patients out of 202 in the ear, $10(7.57 \%)$ patients out of 132 in the nose and none in the throat. Of the total patients, $97(20.08 \%)$ required general anesthesia (GA) to remove FBs and the rest $427(88.4 \%)$ patients were dealt with or without local anesthesia. Most of the FBs were removed promptly on presentation otherwise within 24 hours of presentation in the hospital.
\end{abstract}

Conclusion: FB in ENT were found more commonly in the children and the commonest site was ear. Timely presentation, prompt diagnosis and needful management in a center with otolaryngology practice reduces the morbidity and mortality. Most of the FB in ENT can be removed in outpatient department (OPD) or emergency room (ER) with or without local anesthesia (LA).

Keywords: Ear; Nose; Throat; Foreign Bodies; Local Anesthesia

\section{Introduction}

A foreign body (FB) is any object or substance that is not derived from the individual's own body part and can cause harm by its mere presence if prompt medical care is not provided $[1,2]$. They may be found in Ear, Nose and Throat. They are very common in otorhinolaryngological clinical practice. It can be introduced spontaneously or accidentally by both children and adults. However, children are common victims as they have habit of inserting nearby objects in their nose, ear or mouth, imitation and also other contributing factors are like boredom, playing, mental retardation, insanity, and attention deficit hyperactivity disorder, along with availability of the objects and absence of watchful caregivers. Consequently, it may cause minor irritation to life threatening problem. A proper technique, good light, appropriate instrument, a co-operative or fully restrained patient and a gentle approach by the related doctor or health worker are required for the removal of FB. One should have a clear diagnosis before making attempts to remove the FB so as to lessen the morbidity [3,4]. FB may be classified as animate (living) and inanimate (nonliving). The inanimate FB can again be classified as vegetative (organic) and non-vegetative (inorganic) FB, and hygroscopic (hydrophilic) and non-hygroscopic (hydrophobic) [1,2]. The objective of this study was to evaluate the nature, common sites, modes of presentation, modes of management of FB, age and gender distribution. 


\section{Materials and Methods}

A retrospective study was conducted in the Department of ENT - Head and Neck Surgery, Universal College of Medical Sciences, from March 2014 to September 2017. The data were obtained from the hospital record books. Otoscopy and anterior rhinoscopy were performed to diagnose FB of the ear and nose respectively. Instruments such as Jobson Horne probe, FB hook, Tilley's forceps, and crocodile forceps were used in FB removal from the nose and ear. Syringing and suctioning were also done for FB ear removal. Plain X-ray of the neck was done in patients with a history of FB ingestion. Flexible nasopharyngo laryngoscopy (NPL) and flexible upper gastrointestinal (UGI) endoscopy were done in cases where the FB was not visible in X-ray to rule out presence of a FB or to determine its site of impaction and in selected cases UGI endoscopy was used for FB removal too. It was followed by removal of the FB from the oropharynx/hypopharynx and esophagus with direct laryngoscopy or rigid esophagoscopy, respectively under general anesthesia (GA). FB struck in the oropharynx or parts of hypopharynx were confirmed with the help of Lack's tongue depressor and head light or indirect laryngoscopy and removed with the Tilley's forceps under local anesthesia (LA) in the OPD with patient co-operation.

\section{Results}

There were 483 patients recorded, out of which 287 (59.42\%) were male and $196(40.57 \%)$ were female with male to female ratio 1.46:1. The number of FB (Table 1 \& Figure 1) in ear was 202 (41.82\%), 132 (27.32\%) in nose and 149 (30.82\%) in the throat. Out of 202 FB in ear, 54 (26.73\%) was animate and 148 (73.26\%) inanimate. Out of 132 nasal FB, 10 (7.57\%) was animate and 122 $(92.42 \%)$ was inanimate. The FB encountered in throat was entirely of inanimate nature.

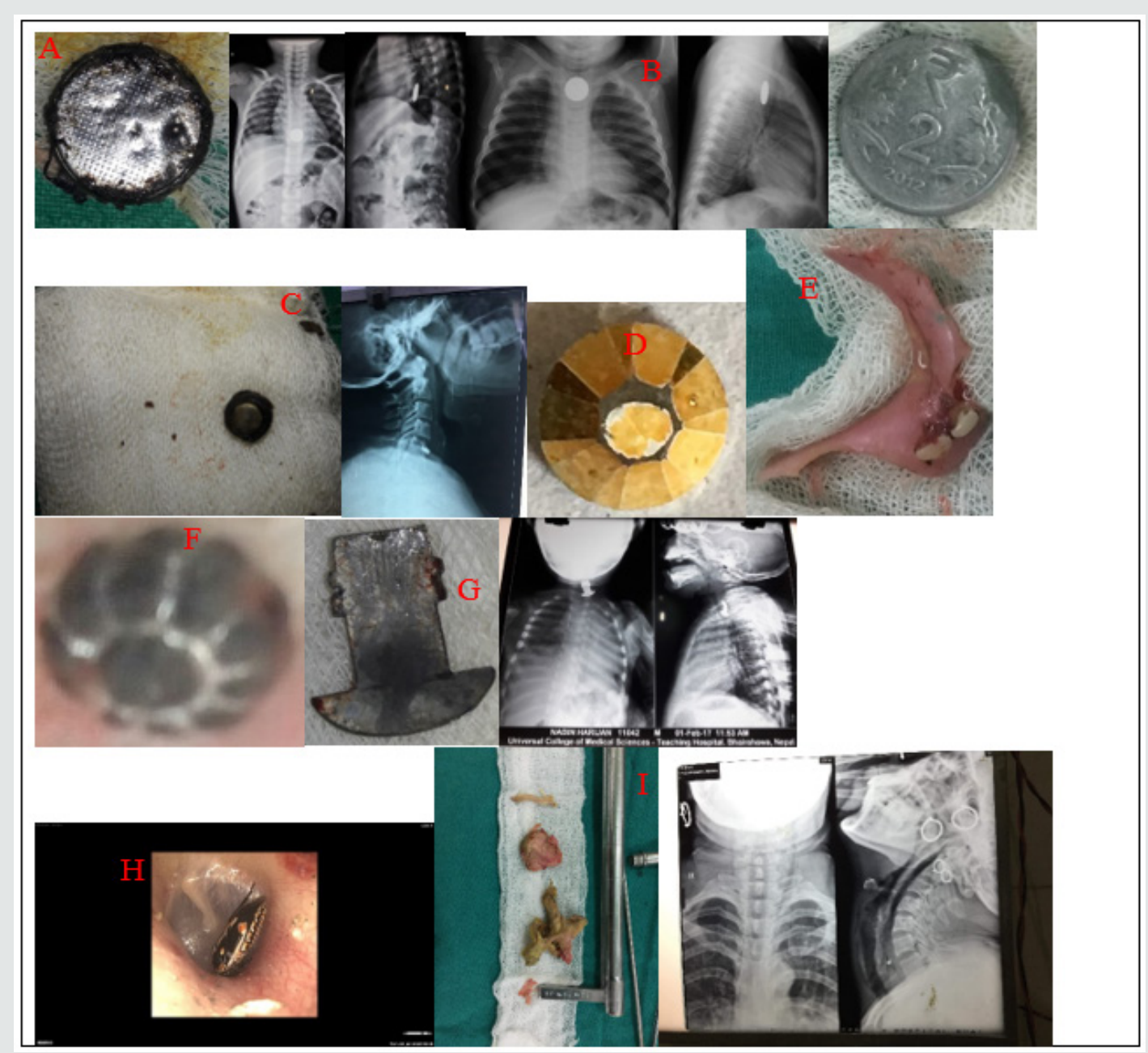

Figure 1: Few examples of ENT foreign bodies. A) FB toy battery in esophagus and removed with rigid esophagoscope, B) FB coin in esophagus, C) FB button battery in esophagus, D) FB bead removed from ear, E) FB denture, F) FB bead removed from nose, G) FB metal hook in esophagus, H) FB insect in ear and I) FB chicken bone with meat bolus in esophagus.

\section{FB in Ear}

Total of 202 patients were recorded with FBs in the ear. The most common type of FB in the ear was grain seed $25.74 \%$ (52) followed by FB bead $19.8 \%$ (40). Fifty-four (26.73\%) patients had animate (living) FBs. These were mostly insects in the form of maggots, cockroach, grasshopper, butterfly, housefly and ticks. Hundred and forty-eight (73.26\%) patients had inanimate (nonliving) FBs. Out of 148 patients, fifty-two (35.13\%) had hygroscopic FBs in the 
form grain seed in the form of bean, pea, wheat, paddy and gram as shown in Table 1 . The rest ninety-six (64.86\%) patients had non-hygroscopic FBs in the form of bead, cotton pledget, pebble, eraser, paper, button batteries, plastic ball and vegetable twig or thorn. Majority of cases were seen in 0-10 years age group i.e. $72 \%$ (147). The most common site of FB lodgement was found to be the external auditory canal. Most of these FBs were removed in the OPD or in the ER with or without local anesthesia (LA). In 4 children, the FB were found impacted in the deeper part of EAC ( 3 button batteries and 1 plastic ball) and had to remove under GA via postaural approach.

\section{FB in the Nose}

Hundred and thirty-two (27.32\%) had FB lodgement in the nose. The most common was grain seed 40 (Out of it, only 10 (7.57\%) patients had living FBs i.e., 9 had maggots and 1 had leech. The rest 122 (92.42\%) patients had nonliving FBs as shown in Table 1. Forty FB (30.3\%) were of hygroscopic nature in the form of grain seed and the rest sixty nine percent being non-hygroscopic as in Table 1 . Of the total number of 132 patients 122 patients $(92.42 \%)$ were children and the rest 10 (7.57\%) patients were adults with animate type of FBs. Hundred and five (86.06\%) of the children presented with history of FB insertion nose by their caretakers, while in 17 (12.87\%) children neither the patients nor the caretakers were certain of FB insertion. Unknowingly, they were treated as a case of sinusitis due to complaints of nasal blockage, headache and unilateral fetid discharge by the pediatricians and primary care physicians, which was later, referred to our center and revealed to be forgotten FB. Sometimes, even one has to depend on imaging like x-rays /CT scans to rule out the FBs where the patients are unable to recall the events. Otherwise, most of the times the typical history provides clue for clinching the diagnosis. Most of the FB were removed in the ER and OPD with or without LA and only 3 cases $(2.27 \%)$ required removal under GA i.e. 2 cases of beads and 1 case of grain seed which on manipulation went posteriorly and also patient being uncooperative.

\section{Foreign Bodies in the Throat}

A total of 149 patients presented with the complaint of ingestion of FB. The most common type of FB was coin of one rupee, 2, 5 and 10 rupees and the common site of the impaction was cricopharyngeal junction in all the 50 patients (33.55\%). The sites of other types of FB impaction were oral cavity, oropharynx, hypopharynx, thoracic esophagus and lower gastro-esophageal sphincter region. All the ingested FB were inanimate, with 84 $(56.37 \%)$ being organic and 65 (43.62\%) being inorganic. Organic FBs were meat bolus and bone (fish, chicken, mutton, and buffalo meat) and one of plum seed. The inorganic FBs included button battery, thorn, denture, coin, and metallic objects as shown in Table 1. Age less than 10 years old were the most common group with FB coin. FBs fish bone and vegetable twig/thorn lodged in oral cavity and oropharynx were removed under LA. Out of 40 FB coin, 10 were dislodged spontaneously via gastrointestinal route, 5 FB meat bolus and 7 FB chicken bone were removed by flexible endoscopy and the rest of the FBs were removed under GA without postoperative complications.

Table 1: Different types of Foreign bodies (FB) in ENT.

\begin{tabular}{|c|c|c|c|c|}
\hline Foreign Body $(n=483)$ & Ear $(n=202)$ & Nose $(n=132)$ & Throat (n=149) & Total \\
\hline Bead & 40 & 30 & 0 & 70 \\
\hline Cotton pledget & 35 & & 0 & 35 \\
\hline Pebble & 20 & & 0 & 20 \\
\hline $\begin{array}{l}\text { Grain seed (bean, gram, paddy, wheat, pea), popcorn } \\
\text { kernel }\end{array}$ & 52 & 40 & 0 & 92 \\
\hline $\begin{array}{l}\text { Insect (maggot, cockroach, leech, butterfly, housefly, } \\
\text { tick) }\end{array}$ & 20 & 10 & 0 & 30 \\
\hline Eraser & 10 & 10 & 0 & 20 \\
\hline Paper & 5 & 7 & 0 & 12 \\
\hline Button battery & 10 & 15 & 2 & 27 \\
\hline Plastic ball & 5 & 10 & 0 & 15 \\
\hline Fish bone & 0 & 0 & 30 & 30 \\
\hline Chicken/mutton/buffalo bone & 0 & 0 & 40 & 40 \\
\hline Vegetable twig/thorn & 5 & 5 & 5 & 15 \\
\hline Denture & 0 & 0 & 3 & 3 \\
\hline Metal & 0 & 5 & 4 & 9 \\
\hline Coin & 0 & 0 & 50 & 50 \\
\hline Meat bolus(chicken/mutton/buffalo) & 0 & 0 & 14 & 14 \\
\hline Fruit seed (plum) & 0 & 0 & 1 & 1 \\
\hline Total & 202 & 132 & 149 & 483 \\
\hline
\end{tabular}




\section{Discussion}

In our study, we've found higher incidence of FB in children less than 10 years old in $66.04 \%$ (319) patients. This is consistent with study by Iseh and Yahya [5], Ogunleye AOA and Sogebi R [6], Ahmad $M$, et al. [7]. This may be consequent of children's exploring habit and lodging objects into the natural orifices of body, accidentally or intentionally. We found $59.42 \%$ of patients to be male and $40.5 \%$ to be female with male: female ratio 1.46:1. The male: female ratio was shown to be 1:1.05 by Gregogri et al. [8] whereas it was 1:1.26 in the study of Ogunleye AO et al. [9] and 1.35:1 by Agrawal S, Ranjit A study [10]. This suggests male are more susceptible than female to foreign body insertion in the orifices. In this study we observed ears were the most common site of lodgement of foreign bodies (41.82\%) followed by throat (27.32\%) and nose (27.32\%). Parajuli R [11] and Shrestha I, et al. [4] also found in their study ears as the most common site for impaction of foreign bodies followed by throat and nose. The most common foreign body in the ear and nose was the variety of grain seeds like bean, pea, paddy, wheat, gram, maize and foreign body coin was highest in throat Removal methods, most commonly used for ear, nose and throat FBs were similar to those presented by Parajuli R [11], in order of preference the alligator forceps, Jobson Horne probe, foreign body hook, Tilley's forceps and ear syringing. No patient required endoscopy or indirect laryngoscopy to remove oropharyngeal FB. The need for general anesthesia to remove FB varies in literature, with percentages varying from $8.6 \%$ to $30 \%$ [12]. There were no complications reported post FB removal.

\section{Conclusion}

FB in ENT are common in both pediatric and adult population. Comparatively the children are seen to be more vulnerable to have ENT FB lodgement. Significant complications may arise if FB in ENT are not taken care of immediately and skillful removal is must. Thus, proper care and watch must be provided by care takers or the family members in order to prevent the encounter of such objects, especially in pediatric group.

\section{References}

1. Carney AS, Patel N, Clarke R (2008) Foreign bodies in the ear and the aerodigestive tract in children. In: Scott-Brown's Otorhinolaryngology, Head and Neck Surgery, ( $7^{\text {th }}$ edn). Edward Arnold, London, UK pp. 11841193.

2. Sarkar S, Roychoudhury A, Roychaudhuri BK (2010) Foreign bodies in ENT in a teaching hospital in Eastern India. Indian J Otolaryngol Head Neck Surg 62(2): 118-120.

3. Hon SK, Izam TM, Koay CB, Razi A (2001) A prospective evaluation of foreign bodies presenting to the Ear, Nose and Throat Clinic, Hospital Kuala Lumpur. Med J Malaysia 56(4): 463-470.

4. Shrestha I, Shrestha BL, Amatya RC (2012) Analysis of ear, nose and throat foreign bodies in dhulikhel hospital. Kathmandu Univ Med J (KUMJ) 10(38): 4-8.

5. Iseh KR and Yahya (2008) Ear foreign bodies Observation on the clinical profile in sokro, Nigeria. Annals of African Medicine 1: 18-23.

6. Ogunleye AOA, Sogebi Roa (2006) Otic foreign bodies. Nigerian Journal of Surgery Research 2: 305-308.

7. Ahmad M, Wagay F, Patigaroo SA et al. (2013) Analysis of ENT foreign bodies and their management in tertiary care hospital. International journal of Basic and Applied Medical Sciences (3): 138-141.

8. Gregori D, Salerni L, Scarinzi C (2008) Foreign bodies in the nose causing complications and requiring hospitalization in children $0-14$ age: Results from the European survey of foreign bodies injuries study. Rhinology 46: 28-33.

9. Ogunleye AO, Sogebi OA (2004) Nasal foreign bodies in the African children. Afr J Med Med Sci 33: 225-228.

10. Sanjay Agrawal, Ambad Ranjit (2017) Study of Nasal Foreign Bodies at a Tertiary Care Hospital in Chhattisgarh. Int J Med Res 3(1): 274-276.

11. Parajuli R (2015) Foreign Bodies in the Ear, Nose and Throat: An Experience in a Tertiary Care Hospital in Central Nepal. Int Arch Otorhinolaryngol 19(2): 121-123.

12. Thompson SK, Wein RO, Dutcher PO (2003) External auditory canal foreign body removal: management practices and outcomes. Laryngoscope 113: 1912-1915.

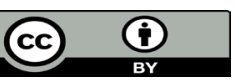

This work is licensed under Creative Commons Attribution 4.0 License

To Submit Your Article Click Here: Submit Article
DOI: $10.32474 /$ SJ0.2019.02.000145

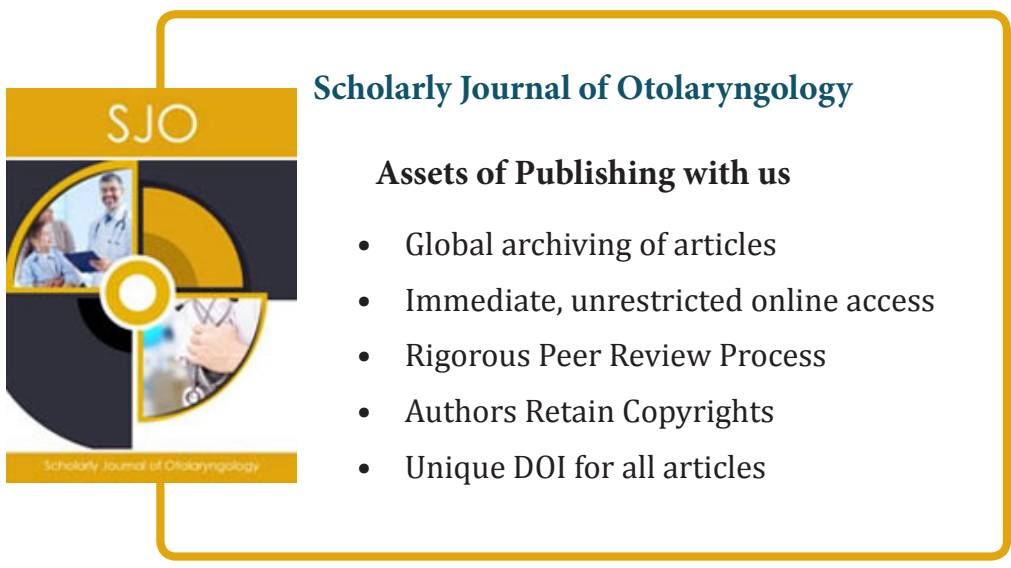

